\title{
Are risk factors for non-communicable diseases in adolescents a problem in senior high schools in Accra?
}

\author{
Delia A. Bandoh, Gifty Sunkwa-Mills and Kenu Ernest
}

Ghana Med J 2020; 54(2)supplement: 59-63 DOI: http://dx.doi.org/10.4314/gmj.v54i2s.10

\author{
${ }^{1}$ Ghana Field Epidemiology and Laboratory Training Programme, School of Public Health, College of Health \\ Sciences, University of Ghana, Legon, Ghana
}

Corresponding author: Delia Akosua Bandoh

E-mail: deliabandoh@gmail.com

\author{
Conflict of interest: None declared
}

\section{SUMMARY}

Background: We assessed risk factors of noncommunicable diseases (NCDs) among adolescents in a senior high school

Design: We conducted a cross-sectional study in 2016

Setting: Senior High School in Accra

Participants: Adolescents in senior high school

Interventions: Adolescents were interviewed with a structured questionnaire designed using the WHO STEPS framework. Data on tobacco use, alcohol consumption, physical activity and physical measurements of respondents were taken.

Main outcome measures: risk factors of noncommunicable diseases among adolescents

Results: A total of 360 adolescents in the school were assessed. Mean age was (17 \pm 1.21$)$ years with minimum age being 13 and maximum 19 years. Females were 51\% (184/360). About 75\% (271/360) reported low physical activity, $15 \%(55 / 360)$ were overweight or obese $(95 \%$ CI: $0.0317-0.078), 7.0 \%(25 / 360)$ consumed alcohol $(95 \%$ CI: $0.054-$ 0.111 ) and $2.5 \%$ (9/360) smoked tobacco (95\%CI: 0.013- 0.048). Majority of the respondents (346/360) were exposed or at risk of developing at least one risk factor. However, no one was found to be at risk of all five risk factors assessed. Females were three times more likely to be overweight or obese compared to their male counterparts (OR:3, 95\%CI:1.581-5.624)

Conclusion: We found that majority of the children had low physical activity and more than $90 \%$ of the respondents had at least one NCD risk factor.

Keywords: noncommunicable diseases, risk factors, physical activity, tobacco use, consumption of alcohol Funding: This work was funded by the authors

\section{INTRODUCTION}

Globally, noncommunicable diseases including cardiovascular diseases, chronic respiratory diseases, cancers and diabetes are the leading cause of death. Every year, about 38 million, representing about two-thirds preventable deaths occur worldwide as a result of Noncommunicable diseases (NCDs). ${ }^{1}$

Three-quarters of the deaths from NCDs (28 million) occur in low- and middle-income countries (LMICs). These countries including sub-Saharan Africa show an increasing burden in spite of the fact that they still struggle with the epidemic of communicable diseases., ${ }^{2,3}$ In Ghana, noncommunicable disease account for $42 \%$ of all deaths. ${ }^{1}$ The detrimental effects of noncommunicable disease on Ghana include poverty due to high medical expenditure, pressure on the already stretched health system and decrease in productivity as person years are reduced. ${ }^{4}$
Harmful use of alcohol, physical inactivity, tobacco use and unhealthy diet are the main modifiable risk factors attributed to these diseases. These modifiable risk factors have also been identified as the leading causes of NCDs among Ghanaians in the adult population. ${ }^{5}$

According to Gujjarlapudi and his colleagues, the risk factors of noncommunicable diseases are associated with modernization which is characterized by availability of energy saving devices and improved transportation. ${ }^{6}$ NCDs are predominantly caused by long exposures to modifiable risk factors such as unhealthy lifestyles and progress very slowly. The development of NCDs from modifiable risk factors are many a time due to failure to diagnose early or mismanagement of health condition. 


\section{Original Article}

About $70 \%$ of NCD related deaths in adults have been found to be as a result of behaviours developed during adolescence (WHO, 2018). ${ }^{2}$

Adolescence is a critical transition period from childhood characterized by key development experience and engagement in high risk lifestyles. ${ }^{7}$ Again, behaviours acquired during adolescence are difficult to change hence the need to ensure they acquire desired behaviours devoid of NCD risk factors. Studies of this sort are therefore essential so that the appropriate actions might be taken to reduce the NCD burden.

Since the health in childhood and adolescence is the foundation for adult health, it is prudent to periodically assess these risk factors especially in young people to institute preventive measures and avoid missed opportunities. ${ }^{8}$ Prevention of NCDs among adolescents can go a long way to improve the health of the individual, their future and the next generation. ${ }^{9}$ In addition, curbing the problem among young people would go a long way to contribute to getting rid of a costly epidemic in Africa due to the high population of young people in the region. ${ }^{4}$ This study therefore sought to assess the prevalence of the main risk factors of noncommunicable diseases in adolescents in a high school in Accra.

\section{METHODS}

A descriptive cross-sectional study was conducted in a senior high school in the Greater Accra region between May and June 2016. Students between the age of 10-19 years in their first and second year, from different sociodemographic backgrounds were interviewed with a structured questionnaire designed using the WHO STEPS framework. Respondents were assessed on five modifiable NCD risk factors namely: physical inactivity, overweight/obesity, unhealthy diet, tobacco use, and alcohol use. The sample size of 180 was determined using a $12 \%$ prevalence of overweight and obesity among school-going adolescents in Greater Accra Region and a confidence interval of $95 \% .^{10,11}$

A three-stage sampling technique was used to select the respondents. Students were first grouped by their form (year groups). In the second stage, each year group was then stratified by their various classes based on the courses offered. One class was randomly selected for each of the courses. In each class, a list of all the students was obtained. Students were assigned numbers according to the class registers. A list of random numbers for all the students in each class was generated using Microsoft Excel random number generator. These students were then identified in the class with their numbers.

\section{Data collection}

Data was collected by face-to face interviews using a structured questionnaire modified from WHO STEPS 1 and 2. The questionnaire collected data on; socio-demographic characteristics, history of tobacco use and alcohol consumption, physical activity, and diet. Weight and height measurements of respondents were taken thrice with calibrated stadiometers, ShorrBoard brand, Weigh and Measure, LLC brand and weighing scale, Seca 803 brand respectively. All measurements were taken using CDC standard procedure. ${ }^{12}$

Physical activity was defined as being involved in vigorous activity for more than 15 minutes three times a week. A student who engaged in vigorous activity for more than 15 minutes three times a week was classified as physically active. Anyone who engages in vigorous activity less than 15 minutes was classified as having low physical activity. Consumption of fast food was used as a proxy for assessing consumption of unhealthy diet.

\section{Data management and analysis}

Classification of overweight and obesity was based on the CDC growth reference standards for children and adolescents. ${ }^{13}$ The measures of height and weight for each individual's age and sex were entered into the Medscape ${ }^{\circledR}$ BMI Calculator to generate z-scores and percentiles. Students were classified as Underweight when the BMI was less than 5th percentile. Overweight was considered if their $\mathrm{BMI} \geq 85$ th percentile but less than the 95th percentile (equivalent to or greater than $25.0 \mathrm{~kg} / \mathrm{m} 2$ but less than $30.0 \mathrm{~kg} / \mathrm{m}^{2}$ ). Obesity was described as BMI $\geq 95$ th percentile (BMI equal to or greater than $\left.30.0 \mathrm{~kg} / \mathrm{m}^{2}\right)$.

Data was entered into Microsoft excel for cleaning and exported to STATA version 13 for analysis. Descriptive statistics, such as frequencies, percentages and range were generated to describe the distribution of variables. The risk factors were presented as frequencies and percentages. A simple logistic regression model was run to determine associations between the socio-demographic characteristics of the respondents and the risk factors of NCDs. Multiple logistic regression was done controlling for all confounders to determine the magnitude of the associations. Level of significance was set at $\mathrm{p}<0.05$.

\section{Ethical Consideration}

Ethical approval for the study was granted by the Ghana Health Service Ethical Review Committee. Consent was obtained from the school authorities. Consent was also sought from the parents whose wards were selected for the study and were below 18 years. Assent was then obtained from these students to be part of the study. Consent was also obtained from students above 18 years before they could be part of the study. 
The study was explained to the students and all their questions answered. All responses obtained were kept confidential. Forms for each individual were kept under lock and key. The electronic data was stored and secured with a password known only to the principal investigator, to prevent access to unauthorized people.

\section{RESULTS}

A total of 360 senior high school students were interviewed. They were between the ages of 13 and 19 years with an average age of (17 \pm 1.2$)$. About half of the students lived in an urban area (Table 1).

Table 1 Demographic characteristics of senior high school student in a selected school, 2016

\begin{tabular}{|c|l|}
\begin{tabular}{|c|} 
Variable \\
Gender
\end{tabular} & Frequency (\%) N=360 \\
\hline \multicolumn{1}{|c|}{ Female } & $176(48.9)$ \\
\hline Age (years) & $184(51.1)$ \\
\hline $\mathbf{1 3}$ & $3(0.83)$ \\
\hline $\mathbf{1 4}$ & $1(0.28)$ \\
\hline $\mathbf{1 5}$ & $30(8.3)$ \\
\hline $\mathbf{1 6}$ & $87(24.2)$ \\
\hline $\mathbf{1 7}$ & $123(34.2)$ \\
\hline $\mathbf{1 8}$ & $67(18.6)$ \\
\hline $\mathbf{1 9}$ & $49(13.61)$ \\
\hline Number of years in the school & \\
\hline $\mathbf{1}$ & $194(53.9)$ \\
\hline $\mathbf{2}$ & $166(46.1)$ \\
\hline Akan & \\
\hline Ewe & $121(33.7)$ \\
\hline Ga/Ga-Adangme & $84(23.4)$ \\
\hline Fante & $41(11.4)$ \\
\hline Northern & $29(1.1)$ \\
\hline Other tribes & $46(12.8)$ \\
\hline Semi-urban & $38(10.6)$ \\
\hline Urban & $93(25.8)$ \\
\hline Not stated & $186(51.7)$ \\
\hline
\end{tabular}

About 7\% (25/360) of the students had ever smoked. Majority of them (271/360) were physically inactive and $15 \%(55 / 360)$ were either overweight or obese (Table 2 ).

Almost half of the respondents $48.9 \%$ (176/360) were exposed to NCDs. Less than 1\% (3/360) were involved in four risk factors and $8 \%(28 / 360)$ were involved in three of the risk factors assessed (Table 3). None of the students was exposed to all five risk factors assessed.

Males had three times higher odds of not being overweight or obese compared to their female counterparts (OR:3, 95\%CI:1.6-5.6)
Table 2 Prevalence of NCD risk factors among Senior High School Students, 2016

\begin{tabular}{|c|c|c|c|c|}
\hline \multicolumn{2}{|l|}{ Risk factor } & \multicolumn{2}{|c|}{ Gender Frequency (\%) } & \multirow[t]{2}{*}{$\chi^{2}$} \\
\hline & Total & Male & Female & \\
\hline $\begin{array}{l}\text { Alcohol consump- } \\
\text { tion }\end{array}$ & & & & 0.19 \\
\hline Never consumed & $332(92.22)$ & $159(90.34)$ & $173(94.02)$ & \\
\hline Consume alcohol & $28(7.78)$ & $17(9.66)$ & $11(5.98)$ & \\
\hline Use of tobacco & & & & 3.08 \\
\hline Never used & $121(97.5)$ & $169(96.02)$ & $182(98.91)$ & \\
\hline Ever used & $9(2.5)$ & $7(3.98)$ & $2(1.09)$ & \\
\hline Physical activity & & & & 0.31 \\
\hline Physically active & $89(24.7)$ & $44(25.00)$ & $45(24.46)$ & \\
\hline $\begin{array}{l}\text { Low physical activ- } \\
\text { ity }\end{array}$ & $271(75.3)$ & $132(75.00)$ & $139(75.54)$ & \\
\hline Overweight/Obese\# & & & & $10.1 *$ \\
\hline $\begin{array}{l}\text { Not } \\
\text { weight/obese }\end{array}$ & $305(84.7)$ & $161(91.48)$ & $144(78.26)$ & \\
\hline Overweight/ obese & $55(15.3)$ & $15(8.52)$ & $40(21.74)$ & \\
\hline Fast food & & & & 0.26 \\
\hline No & $235(65.3)$ & $120(68.18)$ & $115(62.5)$ & \\
\hline Yes & $125(34.7)$ & $56(31.82)$ & $69(37.5)$ & \\
\hline
\end{tabular}

Table 3 Number of NCD risk factors found in the Senior High School students

\begin{tabular}{|l|l|l|l|}
$\begin{array}{l}\text { Number of } \\
\text { risk factors }\end{array}$ & \multicolumn{2}{l}{ Frequency (\%) } & \multirow{2}{*}{$\begin{array}{l}\text { Total (\%) } \\
(\mathbf{N = 3 6 0 )}\end{array}$} \\
\cline { 2 - 3 } & Male & Female & $14(3.9)$ \\
\hline $\mathbf{0}$ & $10(5.7)$ & $4(2.2)$ & $190(52.8)$ \\
\hline $\mathbf{1}$ & $96(54.5)$ & $94(51.1)$ & $125(34.7))$ \\
\hline $\mathbf{2}$ & $56(31.8)$ & $69(37.5)$ & $28(7.8)$ \\
\hline $\mathbf{3}$ & $13(7.4)$ & $15(8.1)$ & $3(0.8)$ \\
\hline $\mathbf{4}$ & $1(0.3)$ & $2(1.1)$ & $0(0.0)$ \\
\hline $\mathbf{5}$ & $0(0.0)$ & $0(0.0)$ & \\
\hline
\end{tabular}

Table 4 Association between NCD risk factors and gender of Senior High School students Risk factor Gender $\quad$ Odds Ratio (95\% Confidence interval)

\begin{tabular}{|l|l|l|l}
\hline & Male & Female & \\
\hline Alcohol consumption & & & \\
\hline Never consumed & $159(90.34)$ & $173(94.02)$ & $0.6(0.3-1.3)$ \\
\hline $\begin{array}{l}\text { Consume alcohol } \\
\text { Use of tobacco }\end{array}$ & $17(9.66)$ & $11(5.98)$ & \\
\hline $\begin{array}{l}\text { Never used } \\
\text { Ever used }\end{array}$ & $169(96.02)$ & $182(98.91)$ & \\
\hline Physical activity & $7(3.98)$ & $2(1.09)$ & \\
\hline Low physical activity & $132(75.00)$ & $139(75.54)$ & \\
\hline Physically active & $44(25.00)$ & $45(24.46)$ & \\
\hline Overweight/Obese & & & \\
\hline Not overweight & $161(91.48)$ & $144(78.26)$ & $\mathbf{3}(\mathbf{1 . 6 - 5 . 6})$ \\
\hline Overweight/ obese & $15(8.52)$ & $40(21.74)$ & \\
\hline & & & \\
\hline
\end{tabular}

\section{DISCUSSION}

Our study sought to assess the prevalence of the main risk factors of noncommunicable diseases; use of tobacco through smoking, use of alcohol, low physical activity, body mass index and consumption of unhealthy diet among adolescents in a senior high school. About nine in ten students were exposed to an NCD risk factor. 
We found that some students had been exposed to tobacco use through smoking, were involved in harmful use of alcohol, took unhealthy diets, were physically inactive, were overweight or obese or were engaged in a combination of these factors. More than two-thirds were however physically inactive.

From our findings, physical inactivity was the risk factor with the highest prevalence. Over three-fourths of the students had low physical activity. This confirms a WHO finding that eight of ten adolescents are not physically active globally. ${ }^{14}$ Physical inactivity is a main risk factor of NCDs. It has been found to continue from adolescence to adulthood therefore a majority of these adolescents are at risk of NCD due to their sedentary lifestyle. ${ }^{15}$ When adolescents are physically active, it improves their cardiovascular system and metabolism among others. ${ }^{16}$ Health directorates could engage school heath coordinators in deliberation of the most effective ways of incorporating physical activity into the school curriculum so that students would be urged to become more physically active.

The rate of consumption of fast foods was less than 10 percent. This is relatively lower compared with a study in India among high school students. ${ }^{6}$ With the epidemiological transition, consumption of fast foods is known to be a very common habit among adolescents. These foods are normally high in calories and are associated with NCDS. ${ }^{17}$

The prevalence of tobacco use through smoking was the lowest of the four risk factors assessed. This is lower than the WHO prevalence for youth using tobacco in Ghana. ${ }^{18}$ This could be attributed to the fact that generally; the prevalence of smoking is relatively low in the country. Also, since society frowns on it, adolescents are not likely to disclose their smoking behaviour. Though only less than one-tenth of adolescents were reported to smoke, they are likely to carry this habit into adulthood thus exposing a large number of people to second-hand smoke which has detrimental effects on one's health. ${ }^{4}$

Almost 1 in 10 of the adolescents were exposed to three or more of the NCD risk factors assessed. Exposure of the adolescents to multiple risk factors of NCDs were generally low. This is similar to studies done in Brazil on risk factors of NCDs among adolescents. ${ }^{19,20}$

Though more than half of the adolescents were exposed to at least one risk factor and can be referred to have low risk of NCDs, these exposures are likely to progress till adulthood and might even worsen if the adolescents are not educated and encouraged to adopt healthy lifestyles. Periodic health outreaches with health talks in senior high schools to assess NCD risk factors and educate students on how to live healthy could encourage them to change some of their lifestyles.

A study in Brazil on risk factors of NCDs found that adolescents who are physically inactive are more likely to be exposed to other NCD risk factors. ${ }^{20}$ This affirms the finding of our study that in addition to their low physical activity majority of the adolescents in this study are at risk of being exposed to other NCD risk factors. As adolescents are exposed to multiple risk factors with lack of adequate healthcare, the burden of NCDs among them is likely to increase leading to detrimental effects to the nation and the world as a whole. ${ }^{21}$

From our study, males were less likely to be overweight/obese compared to their female counterparts. Others studies found females to be more exposed to physical inactivity and unhealthy diets than their male counterparts thus putting them at a higher risk of being overweight/obese than their male counterparts. ${ }^{19,20}$

\section{Study limitations}

Physical inactivity was assessed based on reports of the adolescents. It is therefore likely to be subjective. Also, unhealthy diet was defined by consumption of junk food since consumption of fruits and vegetables was not assessed.

\section{CONCLUSION}

Physical inactivity was the commonest risk factor for noncommunicable diseases among adolescents in senior high schools of Greater Accra Metropolis. Majority of these adolescents were exposed to at least one noncommunicable disease risk factor.

\section{REFERENCES}

1. World Health Organisation (WHO). Noncommunicable diseases facts sheet. WHO, Geneva. 2015. Available: http:/www.who.int/mediacentre/factsheets/fs355/en/. (Accessed December 16, 2017.)

2. Ade A, Chethana KV, Mane A, Hiremath SG. Noncommunicable diseases : Awareness of risk factors and lifestyle among rural adolescents. Int J Biol Medial Res. 2014;3(1):3769-3771.

3. Naghavi M, Forouzanfar MH. Burden of noncommunicable diseases in sub-Saharan Africa in 1990 and 2010: Global Burden of Diseases, Injuries, and Risk Factors Study 2010. Lancet. 2010;381:S95. doi:10.1016/S0140-6736(13)61349-5.

4. Naik R, Kaneda T. Noncommunicable diseases In Africa: Youth are the key to curbing the epidemic and achieving sustainable development. Policy Brief. Population Reference Bureau, Washington. 2015. Available: http://www.prb.org/pdf15/ncds-africa-policybrief.pdf. 


\section{Original Article}

5. WHO. Ghana WHO Country Profile. WHO, Geneva? 2014.

6. Gujjarlapudi C, Kasyapa VB, Ravinder A. Risk factors for noncommunicable diseases (NCD) among High School Students in an Urban Setting. F IJRTSAT 2013;7(2):82-85.

7. World Health Organisation (WHO). Adolescent development. WHO maternal, newborn, child and adolescent health. WHO, Geneva. 2017. Available: http://www.who.int/maternal_child_adolescent/topics/adolescence/dev/en/. (Accessed December 19, 2017.)

8. Nelson F, Nyarko KM, Binka FN. Prevalence of Risk Factors for noncommunicable diseases for New Patients Reporting to Korle-Bu Teaching Hospital. Ghana Med J. 2015;49(1):12-18.

9. Patton G, Sawyer S, Santelli J, Al E. Our future: A Lancet commission on adolescent health and wellbeing. Lancet. 2016;387(10036):2423-2478.

10. Nyawornota VK, Aryeetey R, Bosomprah S, Aikins M. An Exploratory Study of Physical Activity and Over-Weight in Two Senior High Schools in The Accra Metropolis. Ghana Med J. 2013;47(4):197203.

11. Kumah DB, Akuffo KO, Abaka-Cann JE, Affram DE, Osae EA. Prevalence of Overweight and Obesity among Students in the Kumasi Metropolis. $J$ Nutr Metab. 2015; 2015:1-4.

12. Centres for Disease Control and Prevention. Anthropometry Procedures Manual.; CDC, Atlanta. 2007. Available:

http://www.cdc.gov/nchs/data/nhanes/nhanes_07_0 8/manual_an.pdf. (Accessed December 16, 2017.)

13. Onis M, Onyango AW, Borghi E, Siyam A, Nishida C, Siekmann J. Development of a WHO growth reference for school-aged children and adolescents. Bull World Health Organ. 2007; 85(9):660-607.
14. World Health Organization. Physical Activity Fact Sheet. WHO, Geneva. 2014.

15. Mäkinen TE, Borodulin K, Tammelin TH, Rahkonen O, Laatikainen T, Prättälä R. The effects of adolescence sports and exercise on adulthood leisuretime physical activity in educational groups. Int $J$ Behav Nutr Phys Act. 2010. doi:10.1186/1479-58687-27.

16. Andersen LB, Tammelin T. Lack of physical activity and excessive sitting: health hazards for young people? J Pediatr (Rio J). 2009; 85378(47). doi:10.2223/JPED.1936.

17. Ashakiran, Deepthi R. Fast Foods and their Impact on Health. JKIMSU. 2012;1(2).

18. World Health Organisation (WHO). WHO report on the global tobacco epidemic, 2017 Country profile. 2017. http://www.who.int/tobacco/surveillance/policy/country profile/gha.pdf?ua=1. (Accessed December 19, 2017.)

19. Nunes HEG, Goncalves ECDA, Vieira JAJ, Silva DAS. Clustering of risk factors for noncommunicable diseases among adolescents from southern Brazil. PLoS One. 2016;11(7):1-13.

20. Tassitano RM, Carvalho SD, Alejandro D, Chica G, Cecília M, Tenório M. Aggregation of the four main risk factors to noncommunicable diseases among adolescents. Rev BRas epidemiol. 2014:465-478.

21. Nikolic IA, Stanciole AE, Zaydman M. Chronic Emergency: Why NCDs Matter. The International Bank for Reconstruction and Development / The World Bank. Washington. 2011. Available: http://documents.worldbank.org/curated/en/267551468148765055/pdf/639270WP0Ch ron0Box0361533B00PUBLIC0.pdf. (Accessed December 16, 2017.) 